\title{
Monitoring Depth of Discharge of a Valve Regulated Lead Acid Battery in a Standalone PV System
}

\author{
Mirdiansyah ${ }^{1}$ Ahmad Taqwa ${ }^{2}$ Yohandri Bow, \\ ${ }^{1}$ Applied Renewable Energy Engineering Study Program, Politeknik Negeri Sriwijaya, Jalan Srijaya Negara, \\ Palembang, 30139 Indonesia \\ ${ }^{2}$ Renewable Energy Engineering Department, Politeknik Negeri Sriwijaya, Jalan Srijaya Negara, Palembang, 30139 \\ Indonesia \\ ${ }^{3}$ Energy Engineering Department, Politeknik Negeri Sriwijaya, Jalan Srijaya Negara, Palembang, 30139 Indonesia \\ *Corresponding author. Email: yohandrimk.2020@gmail.com
}

\begin{abstract}
The standalone solar power plant system uses batteries as a storage component of electrical energy generated. A charging condition that exceeds the capacity more than $100 \%$ and the battery discharging condition exceeds the discharge depth value (dept of discharge $80 \%$ or state of charge $20 \%$ ) of the battery capacity can shorten the service life. The use of Siemens LOGO! 8.FSA (LOGO OBA8) smart relay can adjust the condition of the discharge of depth (DoD) and overcharging of a battery so that it can be monitored. The capabilities of a smart relay can be made an indicator, alarm, or energize the contactor so that it can prevent or reduce the discharge and overcharging that occurs in the battery which makes the battery life longer.
\end{abstract}

Keywords: Standalone system, Depth of Discharge, Battery, Over Charging, SmartRelay

\section{INTRODUCTION}

A standalone Power System is a system that supplies electricity to users and is not connected to the power distribution system from the power supply authority [13]. In a standalone solar power generation system, the type of battery commonly used is Valve Regulated Lead Acid (VRLA). In addition to a reasonably affordable price, battery life can reach 10 years, depending on the technology and quality of the materials used, load levels, and various other factors $[4,5]$. Apart from being maintenance-free, because this type of battery has a valve for gas exchange, the temperature inside the battery will be maintained, and the battery's lifetime will be maximized [6-8].

Lead acid battery failures can include unavoidable natural failures such as expansion and corrosion of the positive plate, reduced capacity due to physical changes. Other causes of damage are due to the influence of temperature, overcharging, undercharging, DC ripple [9, 10], and the discharge depth level where the cycle test shows significant lead sulfate $\left(\mathrm{PbSO}_{4}\right)$ formation on the negative and positive electrodes. $80 \%$ of DoD can reduce the life cycle. Sulfate formation was observed to decrease at low DoD [11-14].
VRLA batteries are not recommended to drain more than $80 \%$ of their capacity. The maximum capacity are 80\% DoD 1200 cycles, 50\% DoD 2500 cycles and 20\% DoD reaches 5000 cycles [15]. In Figure 1, the higher the depth of discharge of a battery, the cycle time or service life will decrease. It is necessary to limit the DoD value to around $80 \%$ to maintain longer battery life.

The solar charge controller controls battery charging in solar power plants. The selection of the MPPT type controller is based on an efficiency level of up to $30 \%$ and can force solar panels to operate close to the maximum voltage [16-18]. Battery charging is getting better and faster with MPPT (Maximum Power Point Tracking). Generally, MPPT controllers are equipped with battery voltage measurements. There is a voltage measurement provided that can be accessed via the RS 485 serial port or the TCP/IP Modbus port on the latest technology. The advantages of the Modbus protocol that will be used in this study are that it is openly published and royalty-free, is relatively easy to apply to industrial networks, and uses raw bits or words of data without imposing many restrictions and limitations on developers [19]. 
Various attempts have been made by many researchers to create a battery monitoring system, including the Arduino-based Smart Battery Monitor DS2438. In this study, discussed the monitoring of the VRLA battery discharge depth that utilizes the voltage value data on the MPPT type solar charge controller with a TCP/IP Modbus output. Data in the form of voltage is stored in the form of registers that can be read using the MPPT Tristar TS-MPPT-60 controller and processed using a smart relay from Siemens, namely (LOGO! 8.FS4).Smart relays have the advantage of having a display to display program output in the form

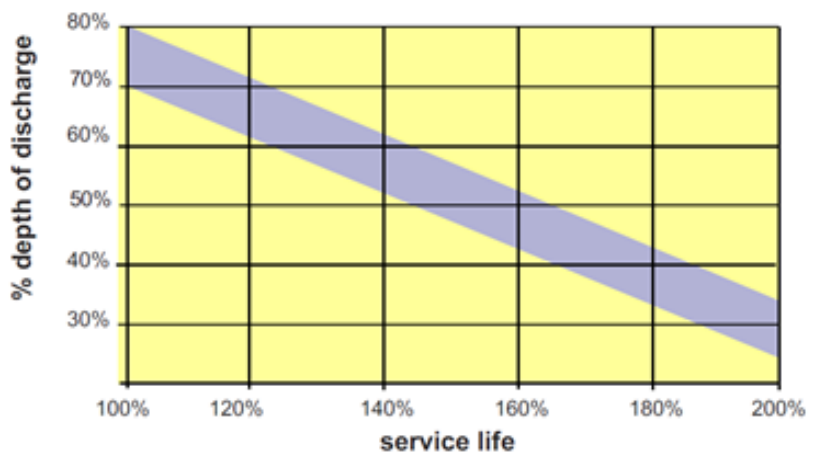

of information from the monitored battery.

Figure 1 Effect of Depth of Discharge on Battery Life [20]

\section{RESEARCH METHODS}

Block diagram of the VRLA battery monitoring system on the standalone PV system information is stored real time in the Tristar TS-MPPT-60 solar charge controller and read by Siemens LOGO! 8.FS4 is first programmed via the Siemens LOGO software! Soft Comport version 8.2.1, as shown in Figure 2. The output of the Siemens (LOGO! 8. FS4) is an indication of the depth of charge, which is the battery rating with a display of numbers, text, and bar graphs on the screen Siemens (LOGO! 8.FS4) which is different in each condition, including the indicator light on the panel box. Besides, other outputs to support monitoring conditions are added with an alarm in the form of a sound when the depth of the charger shows a value of $25 \%$ State of Charge (SoC) or $75 \%$ Depth of Discharge (DoD). There is an output that will function the contactor as a power supply breaker from the solar panel with a timer setting when charging has reached the highest voltage for charging according to the instructions from the battery manufacturer to avoid the overcharge. If there are many types of loads, the loading can be adjusted based on priority, where the load with the highest priority, according to the user, is maintained when the discharge has reached the lowest value starting from $25 \%$ to protect the battery from damage.

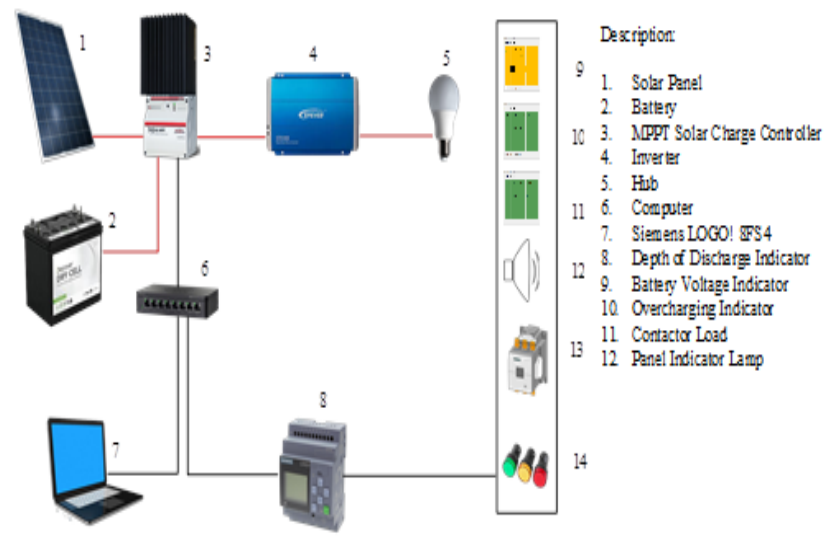

Figure 2 VRLA Battery Monitoring Block Diagram

In previous research, it was found that the relationship between Open Circuit Voltage (OCV) and the State of Charge was a linear. By using a 1400mAh capacity battery, the OCV of the battery when fully charged is 13.18 volts, while 11.8 volts when the battery is completely discharged, as shown in Figure 3 [21, 22].

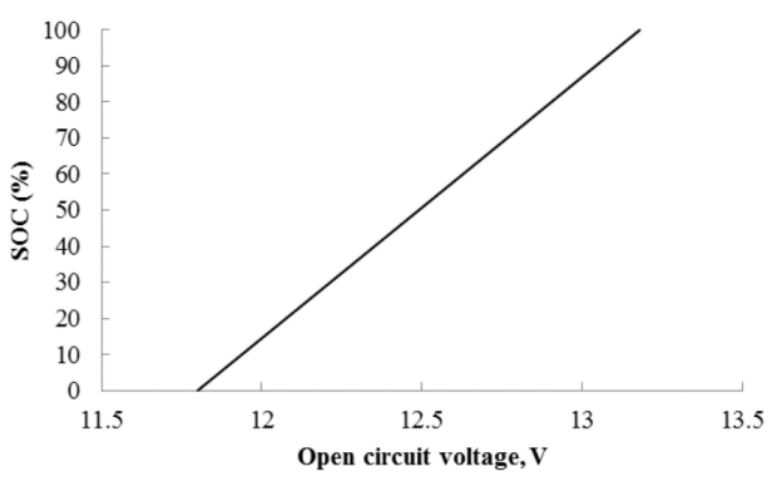

Figure 3 Battery SoC Against OCV [14]

Depth of discharge with a value of more than $80 \%$ on a standalone PV system battery can occur during the rainy season. Increase of DoC happens because the rate of battery charging to discharge is quite different due to the influence of the weather. It takes longer time for charging to reach $100 \%$ capacity compared to discharging with an SoC value of $20 \%$ because the power generated by the solar panels is low due to low sun intensity as in Figure 4.

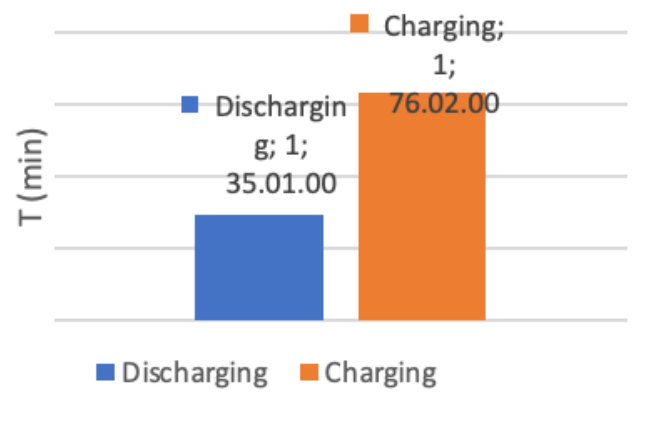

Figure 4 Comparison Chart of Discharging and Charging Time 


\section{RESULTS AND DISCUSSION}

Battery voltage data is required for monitoring the observed battery condition. In the MPPT Tristar TSMPPT-60 solar charge controller, there are current, voltage and temperature sensors that are stored as registers that support the Modbus function, namely read holding registers $03(0 \times 03)$ and read input registers 04 (0x04). Three holding registers are required to be read by the Siemens (LOGO! 8.FS4) smart relay.

The first is the holding register with the protocol data address 0x0000 and logical address 1 variable name V_PU hi. The second is holding registers with data protocol address 0x0001 and logical address 2 variable name V_PU lo. The third is holding register with a data protocol address 0x00018 and a logical address 25 variable names adc_vb_f_med. The register readsin the (LOGO! 8.FS4) smart relay is a decimal number. The registers are processed to produce a voltage value with the equation:

$$
\text { V_PU hi + (V_PU lo / } \left.2^{16}\right) \text {; }
$$

Where in this study, it was observed and tested at the voltage numbers up to $64 \mathrm{~V} \mathrm{dc}$, the two register values were fixed, namely 180 and 0.

V battery= (adc_vb_f_med x 180) / 32768

The value of the highest register and the lowest register of the battery is required to get $\%$ SoC. In this study,the Shoto 6 FMX 150 B brand battery was used. By using the Epever solar station monitor software (V1.95) and the eLOG Tools (V1.1) software as a comparison to the Siemens (LOG! 8.FS4) obtained a graph, as shown in Figure 5. As for $\%$ SoC processed by smart relay using the equation:

$\%$ SoC $=(\operatorname{Reg} 25-\operatorname{Reg}$ Min $) /(\operatorname{Reg}$ Max-Reg Min $) \times 100$
Based on equation (1) and equation (2), using Siemens (LOGO! 8.FS4) smart relay, the graph in Figure 5 is obtained which is almost identical to the comparator (Ep ever) using the MPPT Ep ever Solar Charge Controller software.

Figure 5 shows the relationship between $\%$ SoC and battery voltage is linear. The two graphs are almost identical, which shows that using a smart relay (LOGO! 8.FS4) battery monitoring can be done. An indication of the battery condition can be shown on the output terminal of (Logo! 8.FS4) smart relay and connected to contactors, alarms, and indication lights as safety when the battery condition has reached $20 \%$ SoC ( $80 \%$ DoD), as shown in Figure 6.

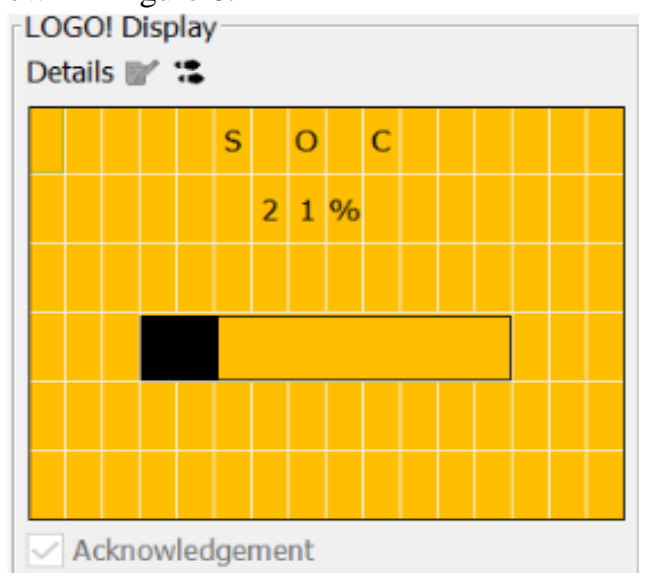

Figure 6 Display of 21\% SoC (79\% DoD)

Charging will stop when the battery voltage reaches a high value of $100 \%$ SoC (14 volts). The full capacity of the battery causes the smart relay to display an indication as in Figure 7 and the smart relay output will energize the contactor to turn off the supply of electrical energy from the solar panel with a time that can be delayed (timer).

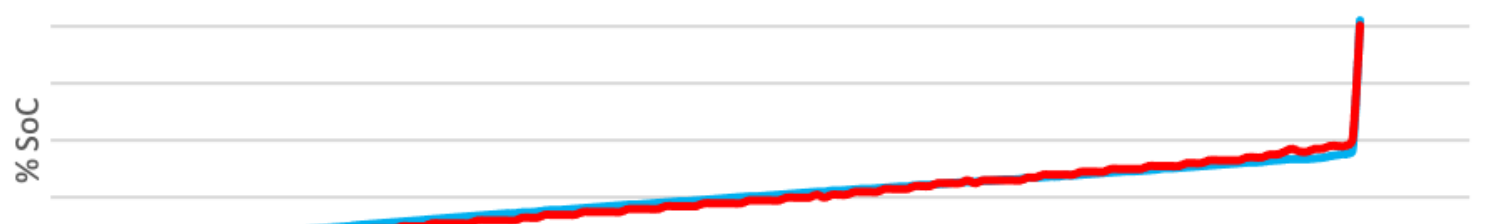

Figure 5 Graph of Smart Relay and Ep ever Battery Discharge Rate 


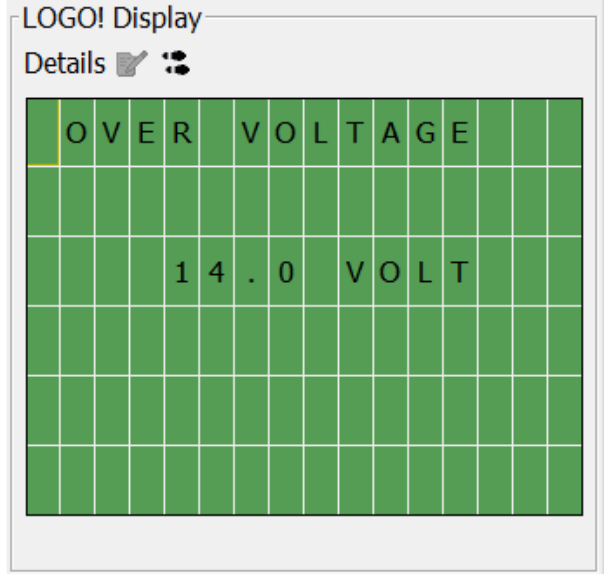

Figure 7 Display of $100 \%$ SoC

The results of the SoC and voltage measurements using (LOGO! 8FS4) are almost close to the comparison with a value difference ranging from 0.1 to 0.3 volts. In Figure 5, there is a sharp decrease from $100 \%$ to $60 \%$ because the Epever software has been programmed for $0 \%$ and $100 \%$ battery capacity. By using a smart relay, the value of $0 \%$ battery capacity and $100 \%$ capacity can be input according to factory specifications through the input of the lowest voltage value and highest voltage input via software as shown in Figure 8. Thus, the voltage value and SoC (DoD) is more accurate and the battery condition can be displayed as in Figure 6 and Figure 7 as well as the output of the smart relay which functions as an alarm and battery saver. For the voltage value, there is a difference between the prototype and the comparison of the average measurement for $\%$ SoC (DoD) of 36 samples. The average difference is 0.12 volts, which means the comparison of the voltage readings contained in the solar charge controller Ep ever is compared to the results of the program process on the smart relay (prototype) using equation (1) of the Tristar TS-MPPT-60 solar charge controller is quite good.

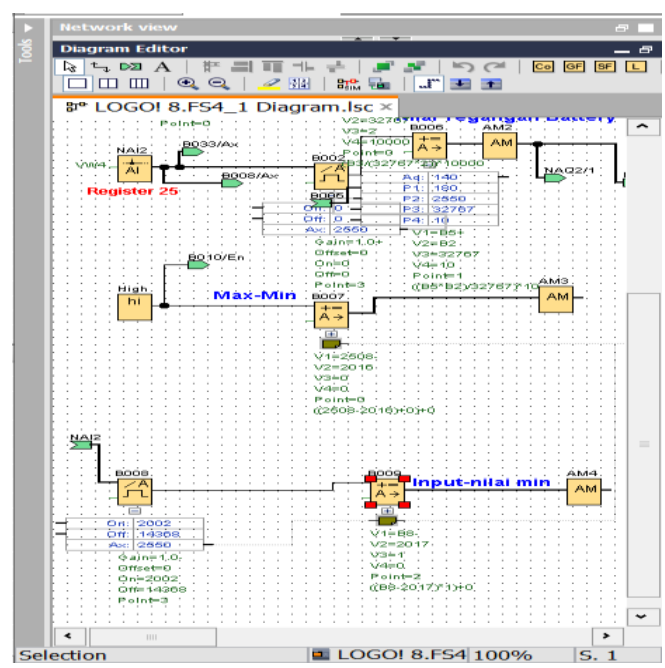

Figure 8 Maximum and Minimum Battery Value Input Program LOGO! 8.FS4
The use of smart relays (LOGO! 8.FS4) as battery monitoring can function both as an alarm system and as a battery protector. With block-based programming of mathematical operation diagrams for various monitoring purposes, it can be done such as Monitoring Dept of Discharge and safety on VRLA batteries that have been carried out. Besides the various conveniences, there are limitations to the calculation where the highest number that can be processed by the smart relay is limited to the value 32768. If in programming, there is processing that exceeds this value, it can be done with manipulation tips and tricks by division. Another limitation is that it cannot process longer programs than that provided by the Siemens smart relay (LOGO! 8.FS4).

\section{CONCLUSION}

The use of smart relays (LOGO! 8.FS4) as battery monitoring can function both as an alarm system and as a battery protector. With block-based programming of mathematical operation diagrams for various monitoring purposes, it can be done such as Monitoring Dept of Discharge and safety on VRLA batteries that have been carried out. Besides the various conveniences, there are limitations to the calculation where the highest number that can be processed by the smart relay is limited to the value 32768 . If in programming, there is processing that exceeds this value, it can be done with manipulation tips and tricks by division. Another limitation is that it cannot process longer programs than that provided by the Siemens smart relay (LOGO! 8.FS4).

\section{AUTHORS' CONTRIBUTIONS}

All of the authors are involved in the process of designing the equipment. The first and corresponding author contribution is responsible for data processing and manuscript writing. The second author is responsible for equipment design and data processing.

\section{ACKNOWLEDGMENTS}

The authors thank to PT Tambang Bukit Asam dan Politeknik Negeri Sriwijaya for the facilities in this research

\section{REFERENCES}

[1] Sammer Saadoon Al-Juboori 2015 Stand-Alone Photovoltaic System

[2] Bart Cotton 2012 VRLA Battery Lifetime Fingerprints - Part 1 .

[3] Didik Hadiyanto, Todo Hotma Tua 2016 Modul Komponen PLTS Terpusat

[4] R Ploetz, R Rusdianasari, and E Eviliana 2016 Renewable Energy: Advantages and Disadvantages Proceeding Forum in Research, Science, and Technology (FIRST) 
[5] PowerThru 2014 Lead Acid Battery Working Lifetime Study

[6] Budiman H, Taqwa A, Kusumanto RD, Rusdianasari, and Dewi T 2018 Synchronization and Application of IoT for on Grid Hybrid PVWind System 2018 International Conference on Applied Science and Technology (iCAST) IEEE 617-621

[7] Suwarno,Irawan 2018 Effect Of Depth Of Discharge On Morphology And Size Of Sulfate Particles In VRLA Battery Electrodes

[8] Hamdi BRD M, Dewi T, Rusdianasari 2019 Performance Comparison of 3 Kwp Solar Panels Between Fixed and Sun Tracking in PalembangIndonesia IOP Conference Series: Earth and Environmental Science 347(1) 012131

[9] Rajarshi Sen, CES 2018 Solar PV Battery Manual

[10] Tulika Majaw, Reeny Deka, Shristi Roy, Bikramjit Goswami 2018Solar Charge Controllers usingMPPT and PWM

[11] A Kurniawan, A Taqwa, Y Bow 2019 PLC Application as an Automatic Transfer Switch for on-grid PV System; Case Study Jakabaring Solar Power Plant Palembang, Indonesia Journal of Physics: Conf. 1167012026

[12] Teguh Arifianto W, Suwito, Pujiono 2011 Implementasi Protokol Modbus Pada Mikrokontroler Atmega16 untuk Pengembangan Level Transmitter dan Gas Transmitter

[13] Eurobat 2003 Eurobat Guide For Motive Power VRLA Batteries

[14] Yee Wan Wong, Lee Wai Chong, Rajparthiban Kumar Rajkumar, Wah Yew Leng, Rajprasad Kumar Rajkumar 2017 A New State-Of-Charge Estimation Method For Valve Regulated Lead Acid Batteries

[15] Edward A, Dewi T, Rusdianasari 2019 The effectiveness of Solar Tracker Use on Solar Panels to TheOutput of The Generated Electricity Power IOP Conference Series: Earth and Environmental Science 347(1) 012130

[16] Zhafarina I N, Dewi T, and Rusdianasari 2018 Analysis of Maximum Power Reduction Efficiency of Photovoltaic System at PT. Pertamina (Persero) RU III Plaju VOLT: Jurnal Ilmiah Pendidikan Teknik Elektro 3(1) 19-25.

[16] Sasmanto A A, Dewi T, Rusdianasari 2020 Eligibility Study on Floating Solar Panel Installation over Brackish Water in Sungsang, South Sumatra EMITTER International Journal of Engineering Technology 8(1)

[17] Harahap H A, Dewi T, and Rusdianasari 2019 Automatic Cooling System for Efficiency and Output Enhancement of a PV System Application in Palembang, Indonesia Journal of Physics: Conf. 1167012027

[18] Taqwa A, Budiman, Kusumanto RD, Rusdianasari, and Dewi T 2018 Synchronization and Application ofIoT for on Grid Hybrid PV-Wind System 2018 International Conference on Applied Science and Technology (iCAST) IEEE 617-621

[19] Y Bow, T Dewi, A Taqwa, Rusdianasari, Zulkarnain 2018 Power Transistor 2N3055 as a Solar Cell Device 2018 International Conference on Electrical Engineering and Computer Science (ICECOS)

[20] A Taqwa, 2019 Higher Education Role in Supporting Indonesia Government Policy in Developing Renewable EnergyJournal of Physics: Conf.1167012010

[21] N Pasaribu, Rusdianasari, A Syarif 2019 Efficiency of $9 \mathrm{KWp}$ Sun Tracking Photovoltaic in Palembang, Indonesia IOP Conference Series: Earth and Environmental Science 347(1) 012129 